\title{
Inflammation Drives Retraction, Stiffening, and Nodule Formation via Cytoskeletal Machinery in a Three-Dimensional Culture Model of Aortic Stenosis
}

Jina Lim, ${ }^{*}$ Arshia Ehsanipour, ${ }^{\dagger}$ Jeffrey J. Hsu, ${ }^{\ddagger}$ Jinxiu Lu, ${ }^{\S}$ Taylor Pedego,${ }^{\ddagger}$ Alexander Wu, ${ }^{\ddagger}$ Chris M. Walthers, Linda L. Demer, ${ }^{\dagger \ddagger \delta}$ Stephanie K. Seidlits, ${ }^{\dagger}$ and Yin Tintut ${ }^{\ddagger \S \uparrow}$

From the Departments of Pediatrics, ${ }^{*}$ Bioengineering, ${ }^{\dagger}$ Medicine,${ }^{\ddagger}$ Physiology, ${ }^{\S}$ and Orthopaedic Surgery, ${ }^{\curvearrowleft}$ University of California, Los Angeles, Los Angeles, California

Accepted for publication

May 5, 2016.

Address correspondence to Yin Tintut, Ph.D., The David Geffen School of Medicine, University of California, Los Angeles, Center for the Health Sciences, A2-237, 10833 Le Conte Ave., Los Angeles, CA 90095-1679. E-mail: ytintut@ mednet.ucla.edu.

\begin{abstract}
In calcific aortic valve disease, the valve cusps undergo retraction, stiffening, and nodular calcification. The inflammatory cytokine, tumor necrosis factor (TNF)- $\alpha$, contributes to valve disease progression; however, the mechanisms of its actions on cusp retraction and stiffening are unclear. We investigated effects of TNF- $\alpha$ on murine aortic valvular interstitial cells (VICs) within three-dimensional, freefloating, compliant, collagen hydrogels, simulating their natural substrate and biomechanics. TNF- $\alpha$ increased retraction (percentage of diameter), stiffness, and formation of macroscopic, nodular structures with calcification in the VIC-laden hydrogels. The effects of TNF- $\alpha$ were attenuated by blebbistatin inhibition of myosin II-mediated cytoskeletal contraction. Inhibition of actin polymerization with cytochalasin-D, but not inhibition of Rho kinase with Y27632, blocked TNF- $\alpha$-induced retraction in three-dimensional VIC hydrogels, suggesting that actin stress fibers mediate TNF- $\alpha-$ induced effects. In the hydrogels, inhibitors of NF-KB blocked TNF- $\alpha$-induced retraction, whereas simultaneous inhibition of c-Jun N-terminal kinase was required to block TNF- $\alpha$-induced stiffness. TNF- $\alpha$ also significantly increased collagen deposition, as visualized by Masson's trichrome staining, and upregulated mRNA expression of discoidin domain receptor tyrosine kinase 2, fibronectin, and $\alpha$-smooth muscle actin. In human aortic valves, calcified cusps were stiffer and had more collagen deposition than noncalcified cusps. These findings suggest that inflammation, through stimulation of cytoskeletal contractile activity, may be responsible for valvular cusp retraction, stiffening, and formation of calcified nodules. (Am J Pathol 2016, 186: 2378-2389; http://dx.doi.org/10.1016/j.ajpath.2016.05.003)
\end{abstract}

Calcific aortic valve disease (CAVD) is the most common valve disease in developed countries, but the only effective treatment currently available is invasive valve replacement. Surgical and transcatheter replacement procedures remain expensive and suboptimal, especially for younger patients. Approximately half of patients with CAVD die within 2 years of symptom onset. ${ }^{1}$ Once the narrowing is severe, 5 -year survival is only approximately $25 \%$. $^{2}$ Lindroos et $\mathrm{al}^{3}$ and Otto and colleagues ${ }^{4,5}$ have reported that even in the absence of hemodynamically significant obstruction of left ventricular outflow, valvular calcification, which is present in approximately $25 \%$ of those aged 65 to 74 years, is associated with higher risk of cardiovascular events. ${ }^{4}$ Thus, as the population ages and CAVD incidence and prevalence increase rapidly, it is critical to develop a better understanding of the mechanisms underlying the development of CAVD. Ultimately, CAVD progresses to severe hemodynamic compromise, with insufficient blood supply to the

Supported by NIH grants DK081346-S1, HL114709, HL121019, and HL007895; UCLA Children's Discovery and Innovation Institute Harry Winston Fellowship Award (J.L.); the University of California, Los Angeles, Henry Samueli School of Engineering and Applied Sciences (S.K.S. and A.E.); and an award from the UCLA Specialty Training and Advanced Research (STAR) Program (J.J.H.). The California NanoSystems Institute Advanced Light Microscopy/Spectroscopy Shared Resource Facility at UCLA was supported with funding from NIH and National Center for Research Resources shared resources grant CJX1-443835-WS-29646 and National Science Foundation Major Research Instrumentation Program grant CHE-0722519.

Disclosures: None declared. 
body because the valve cusps are too stiff to open. ${ }^{6}$ Common features of CAVD are stiffening (aortic sclerosis), retraction, and formation of calcified nodules and calcified deposits progressing to bone formation. In general, such changes in tissues have been associated with inflammatory diseases. ${ }^{7}$

Inflammation is also associated epidemiologically with an increased risk of CAVD. ${ }^{8-10}$ Higher levels of circulating proinflammatory cytokines, such as tumor necrosis factor (TNF)- $\alpha$, are associated with a higher prevalence of atherosclerosis ${ }^{11}$ and a greater progression of aortic valve stenosis. ${ }^{12}$ Using a murine model of aortic valve disease, low-density lipoprotein receptor null $\left(\mathrm{Ldlr}^{--}\right)$mice, Towler and colleagues ${ }^{13}$ found that TNF- $\alpha$ serum levels were increased and, most importantly, that treatment with infliximab, a neutralizing antibody to TNF- $\alpha$, significantly attenuated aortic valve calcification. In further support of their results, we found, using the same model, that TNF- $\alpha$ protein expression was increased locally in the aortic valve cusps. ${ }^{14}$ TNF- $\alpha$ also induces cytoskeletal reorganization and stress fiber formation in fibroblasts, ${ }^{15}$ providing evidence for a role of inflammation in tissue stiffening. However, it is still not clear whether TNF- $\alpha$ directly alters actin cytoskeleton and stress fiber formation in valvular cells and/or whether it contributes directly to valvular cell contraction and tissue stiffness.

Valvular interstitial cells (VICs) contribute to the mechanical characteristics vital for maintaining the unique dynamic behavior of the valve cusps. ${ }^{16}$ Most VICs are quiescent fibroblasts; however, $<5 \%$ are described as myofibroblasts and/or smooth muscle cells. ${ }^{6,16}$ It is not clear whether these latter cells are merely activated fibroblasts, given that fibroblast cultures, including dermal fibroblasts, are known to have some expression of the smooth muscle/ myofibroblast markers, $\alpha$-smooth muscle actin ( $\alpha$-SMA), and myosin, ${ }^{17,18}$ and changes in the phenotype of these cells are dynamic and reversible. ${ }^{19}$ Proliferation of VICs appears to be regulated by transforming growth factor- $\beta$ and the Wnt3a/ $\beta$-catenin pathway. ${ }^{20,21}$ Pioneering studies have found that VICs undergo fibrosis, form nodular structures, and produce calcified matrix ${ }^{22-24}$ and that varying the degree of extracellular matrix stiffness causes VICs to differentiate along a spectrum of lineages from osteogenic and chondrogenic to contractile myofibroblastic lineages. ${ }^{24-26}$ However, it is not clear what initiates these changes in the matrix of aortic valve cusps. We hypothesized that chronic inflammation triggers tissue stiffening, leading to retraction and formation of nodules. We tested the effects of TNF- $\alpha$ on the mechanisms of tissue stiffening, an active process that involves cytoskeletal contraction and reorganization as well as a passive process that involves fibrous protein deposition.

\section{Materials and Methods}

\section{Materials}

Human TNF- $\alpha$ was purchased from R\&D Systems (Minneapolis, MN). Y27632 was from Cayman Chemicals
(Ann Arbor, MI). Pyrrolidine dithiocarbamate (PDTC), blebbistatin, cytochalasin $\mathrm{D}$, and phalloidin were from Sigma (St. Louis, MO). Caffeic acid phenethyl ester and c-Jun N-terminal kinase (JNK) inhibitor SP600125 were purchased from EMD Millipore (Billerica, MA). Masson's modified trichrome stain kit was from IMEB Inc. (San Marcos, CA). Rat-tail type I collagen was from Corning (Corning, NY). Anti-phospho-IкB antibody was from Lifespan Biosciences (Seattle, WA); AlexaFluor $5552^{\circ}$ antibody was from Life Technologies (Carlsbad, CA). Antiphospho-Smad1,5,8 antibody was from Cell Signaling (Beverly, MA). Hydroxyproline kit was purchased from BioVision (Milpitas, CA). Deidentified human aortic valve tissues were obtained with an institutional review board exemption from surgical specimens through the Translational Pathology Core Laboratory of the UCLA Department of Pathology and Laboratory Medicine.

\section{Secondary Harmonic Generation Microscopy}

Human aortic valves were fixed in $4 \%$ paraformaldehyde and embedded in OCT. Then $10-\mu \mathrm{m}$ cryosections were stained with HCS CellMask Green (Fisher, Waltham, MA) and DAPI (Invitrogen, Carlsbad, CA). Secondary harmonic generation microscopy was performed by multiphoton excitation at 860 $\mathrm{nm}$ to image collagen fibrils. ${ }^{27}$ The specimens were imaged at $63 \times$ numerical aperture 1.4 oil-immersion objective on a Leica TCS SP2 acousto-optic beamsplitter multiphoton confocal laser scanning microscope paired with a SpectraPhysics Mai-Tai Ti:Sapphire laser. CellMask Green was imaged using $496 \mathrm{~nm}$, and DAPI was imaged using $780 \mathrm{~nm}$ light, as described. ${ }^{28}$

\section{VIC Culture}

Aortic valve leaflets were carefully excised from C57BL/6 mice, and VICs were cultured on collagen/gelatin-coated plates via an explant technique, as previously described. ${ }^{14}$ Briefly, all three aortic valve cusps were excised from mouse hearts under a dissecting microscope. For each harvest, the cusps from three to five mice were all placed in a $60-\mathrm{mm}$ tissue culture dish that had been coated with $50 \mu \mathrm{g} /$ $\mathrm{mL}$ of collagen and $0.1 \%$ gelatin solution. Cells were allowed to grow until confluent, and the culture was split and propagated in Dulbecco's modified Eagle's medium (DMEM; Cellgro) supplemented with 15\% fetal bovine serum (FBS), penicillin, and streptomycin. For osteoblastic differentiation, cells were cultured in $\alpha$-minimum essential medium (Cellgro) supplemented with $10 \%$ FBS, penicillin, streptomycin, sodium pyruvate, $5 \mathrm{mmol} / \mathrm{L} \beta$-glycerophosphate, $50 \mu \mathrm{g} / \mathrm{mL}$ of ascorbic acid, and the indicated agent(s).

\section{Lentiviral Transduction}

Lentiviral transduction of VICs with control shRNA or Smad6 shRNA were previously described. ${ }^{14}$ Briefly, at 
$50 \%$ confluency, VICs plated in 60-mm dishes were transduced with transduction-ready lentiviral particles carrying control or Smad6 shRNA (Santa Cruz Biotechnology, Dallas, TX) at $2.5 \times 10^{5}$ infectious units of virus per dish. After a 24-hour incubation, the viral particles were removed, and the cells were cultured in DMEM supplemented with $15 \%$ FBS. The VICs that expressed the shRNAs was selected by puromycin $(2 \mu \mathrm{g} / \mathrm{mL}$; Santa Cruz Biotechnology) resistance.

\section{Three-Dimensional VIC Hydrogels}

A three-dimensional collagen hydrogel (3-D VIC hydrogel) model, a free-floating and compliant substrate, modified from that developed by Bell and colleagues, ${ }^{29}$ was used. Fresh collagen solutions were prepared for each experiment, on ice, using $10 \% 10 \times$ DMEM, $80 \%$ type I rat tail collagen, $5 \% 0.1 \mathrm{~N} \mathrm{NaOH} / \mathrm{HEPES} /$ bicarbonate solution, and 5\% sterile water. Cells in $1 \times$ DMEM were added at $3 \%$; the solution was placed into silicone molds (Grace Biolabs, Bend, OR) and polymerized for 35 minutes at $37^{\circ} \mathrm{C}$. The free-floating 3-D VIC hydrogels were subsequently transferred into culture dishes that contained treatment media. The final concentration of collagen per gel was $2 \mathrm{mg} / \mathrm{mL}$. For osteoblastic differentiation and mineralization, cells were maintained in $\alpha$-MEM supplemented with $10 \%$ FBS, $5 \mathrm{mmol} / \mathrm{L} \beta$-glycerophosphate, and $50 \mu \mathrm{g} / \mathrm{mL}$ of ascorbic acid with the indicated agent. Media was replaced with fresh media and agents every 3 to 4 days.

\section{Mechanical Properties of Hydrogel and Tissue Samples}

\section{Hydrogel Retraction}

The 3-D VIC hydrogels were seeded with VIC and cultured with agents, and their diameters were measured, as described by Bell et al, ${ }^{29}$ on the indicated days of culture. Hydrogel retraction was measured as the percentage change in gel diameter normalized to day 0 diameter in quintuplicate per treatment group.

\section{Instron Analysis}

For the 3-D VIC hydrogels, VICs were seeded and cultured with agents, as indicated. For deidentified human aortic valves, specimens were obtained on the day of surgery. Linear compressive testing was performed on samples of hydrogel and the fresh (unfixed) tissue at room temperature using an Instron 5564 material testing device attached to a $2.5 \mathrm{~N}$ load cell (Instron, Norwood, MA). Each sample was compressed at a constant strain rate of $1 \mathrm{~mm} / \mathrm{min}$ to at least 40\% strain. BlueHill 2 software version 2.2.348 (Instron, Norwood, MA) was used for data acquisition. Compressive testing was performed in quintuplicate per treatment group. Data were analyzed with Matlab software version R2015a 8.5.0.197613 (Mathworks, Natick, MA) to calculate Young's compressive modulus from the linear portion of the slope of each stress-strain relationship with Young's compressive modulus:

$$
E(\mathrm{~Pa})=\sigma / \varepsilon
$$

where stress $\sigma=$ force/area, and strain $\varepsilon=\Delta \mathrm{L} / \mathrm{L}_{\mathrm{o}}$ (probe displacement of the hydrogel/the original height of the hydrogel).

\section{Alkaline Phosphatase Activity Assay}

VICs were seeded in 96-well plates and treated as indicated. Alkaline phosphatase cytochemistry, normalized to cell count, was quantified using ImageJ software version 1.49 (NIH, Bethesda, MD; http://imagej.nih.gov/ij).

\section{Matrix Calcification}

Hydrogels were cultured for the indicated days then washed with $1 \times$ PBS, fixed in $4 \%$ paraformaldehyde for 30 minutes at room temperature, washed with $0.05 \%$ Tween-20/PBS, permeabilized with $0.1 \%$ Triton $\mathrm{X}-100$ for 15 minutes, then washed with $0.05 \%$ Tween- $20 / \mathrm{H}_{2} \mathrm{O}$. Hydrogels were stained with Alizarin Red (Sigma) at $2 \mathrm{~g} / \mathrm{mL}$ for 1 hour then washed with $0.05 \%$ Tween- $20 / \mathrm{H}_{2} \mathrm{O}$. Nuclei were counterstained with DAPI. Hydrogels were then carefully mounted on glass slides using Fluormount and imaged. The calcified areas, normalized to total area of the gel or cell number, were quantified using ImageJ software version 1.49 or Metamorph Advanced version 7.7 (Molecular Devices, Sunnyvale, CA).

\section{Immunofluorescence}

Vimentin and $\alpha$-SMA

Murine VICs were grown on 8-well chamber slides coated with collagen/gelatin; washed, fixed, incubated overnight with antivimentin, anti-von Willebrand factor, or anti- $\alpha$ SMA on confluence; and visualized using secondary antibody conjugated with Alexa Fluor 488.

\section{I $\kappa$ B and Phospho-Smad1/5/8}

The 3-D VIC hydrogels were treated as indicated for 8 days, embedded in OCT, snap frozen in 2-methylbutane, and cut into sections. The slides where then fixed with $4 \%$ paraformaldehyde, stained with antibody to phosphophorylated$\mathrm{I} \kappa \mathrm{B}$, and visualized using $2^{\circ}$ antibody conjugated with Alexa Fluor 555. Nuclei were counterstained with DAPI. Fluorescence intensity of the images was quantified for each image and normalized per nuclei count by DAPI using image analysis software (Metamorph Advanced version 7.7).

\section{Western Blotting}

VICs were plated in 6-well dishes and treated with TNF- $\alpha$ as indicated. Whole cell lysates were then extracted. Western analysis of whole cell lysates was probed with anti-

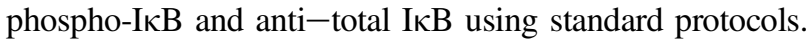




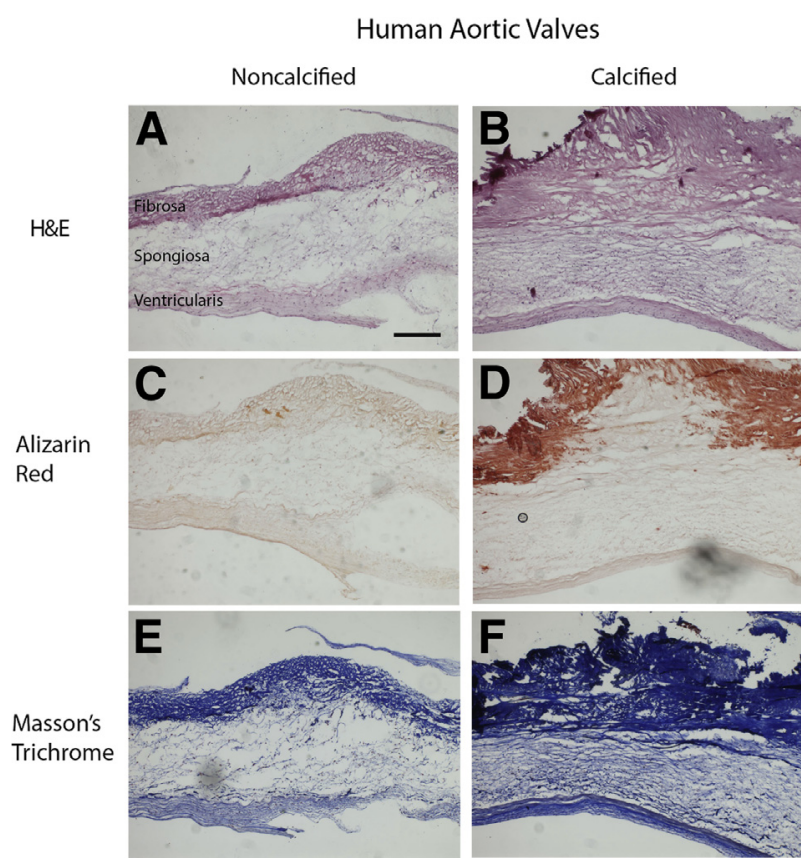

Figure 1 Histologic microscopy of collagen architecture and cusp phenotype in calcific aortic valve disease. Ten-micrometer cryosectioned human aortic valve cusps were stained for structural analysis by hematoxylin and eosin (H\&E) (A and B), for calcification by Alizarin Red (C and D), and for collagen content by Masson's trichrome (E and $\mathbf{F})$. Scale bar $=200 \mu \mathrm{m}$.

\section{Hydroxyproline Assay}

VICs were plated in 6-well dishes and treated with TNF- $\alpha$ for 14 days. Collagen content was assessed in whole cell lysates per the manufacturer's suggested protocol.

\section{Fluorescent Labeling of Filamentous Actin}

VICs were cultured on 8-well chamber slides and treated with vehicle control or TNF- $\alpha$ for 7 days. Cells were washed twice with PBS, fixed, permeabilized with $0.2 \%$ Triton X-100, stained with $10 \mu \mathrm{g} / \mathrm{mL}$ of phalloidintetramethylrhodamine and DAPI for 30 minutes, and visualized by fluorescence microscopy.

\section{RNA Isolation and Real-Time Quantitative RT-PCR}

Total RNA was isolated using TRIzol reagent. Real-time PCR was performed using gene specific primers (One-Step RT-qPCR SuperMix Kit, BioChain Inc., Newark, CA) and MX3005P (Stratagene, La Jolla, CA). Primer sequences included Ddr2: forward: 5'-ATCACAGCCTCAAGTCAGTGG-3', reverse: 5'-TTCAGGTCATCGGGTTGCAC-3'; fibronectin: forward: $5^{\prime}$-TTCAAGTGTGATCCCCATGAA-3', reverse: 5'-CAGGTCTACGGCAGTTGTCA-3'; Acta2: forward: 5'-GTCCCAGACATCAGGGAGTAA-3', reverse: 5'-TCGGATACTTCAGCGTCAGGA-3'; and $\beta$-actin: forward: $5^{\prime}$-GGCTGTATTCCCCTCCATCG-3', reverse: 5'-CCAGTTGGTAACAATGCCATGT-3'. Values were normalized to the internal control gene Actb.

\section{Statistical Analysis}

Experiments were performed with $\geq 3$ replicates with $\geq 3$ samples in each experimental condition, and data were expressed as means \pm SEM. Results were compared using a two-tailed $t$-test. Comparisons across more than two groups were analyzed by one-way analysis of variance, followed by Tukey post-hoc analysis. $P<0.05$ was considered statistically significant.

\section{Results}

\section{Collagen Architecture and Cusp Phenotype in CAVD}

Human aortic valve cusps, obtained from aortic valve replacement surgery, were subjected to histologic analysis. The fibrosa layer was markedly thicker in the calcified cusps (Figure 1, A and B), and Alizarin Red staining revealed calcification in the fibrosa layer of the cusps (Figure 1, C and D). By Masson's trichrome staining, collagen fibers were more densely packed in all three layers (fibrosa, spongiosa, ventricularis) in the calcified cusps (Figure 1, E and F).

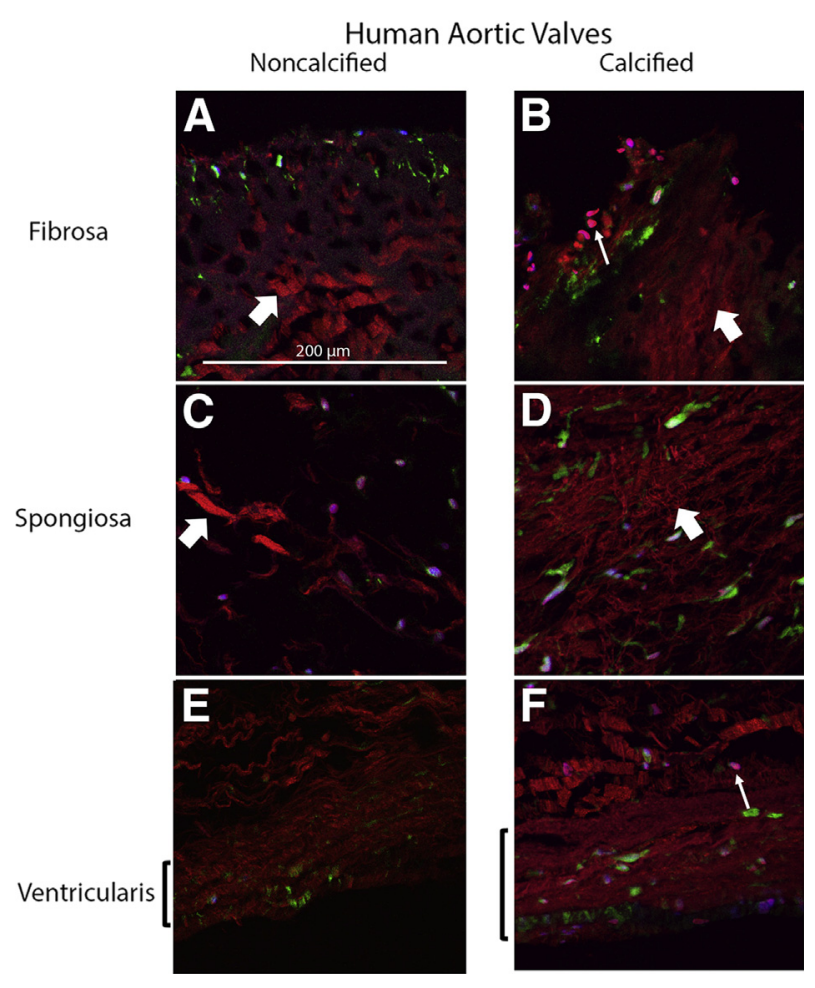

Figure 2 Second harmonic generation microscopy of collagen architecture and cusp phenotype in calcific aortic valve disease. Tenmicrometer cryosectioned human aortic valve cusps, fibrosa layer (A and $\mathbf{B}$ ), spongiosa layer ( $\mathbf{C}$ and $\mathbf{D})$, and ventricularis ( $\mathbf{E}$ and $\mathbf{F}$ ) were imaged for collagen fibril architecture by multiphoton excitation at 860 $\mathrm{nm}$ (red), cell contour (CellMask green) at $496 \mathrm{~nm}$, and nuclei (blue, DAPI) at $780 \mathrm{~nm}$. In the calcified valve cusps (B, D, and F), collagen fibers have greater disorganization (thick arrows) and cellularity (thin arrows) compared with the noncalcified valve cusps (A, C, and E). Scale bar $=200 \mu \mathrm{m}$. 

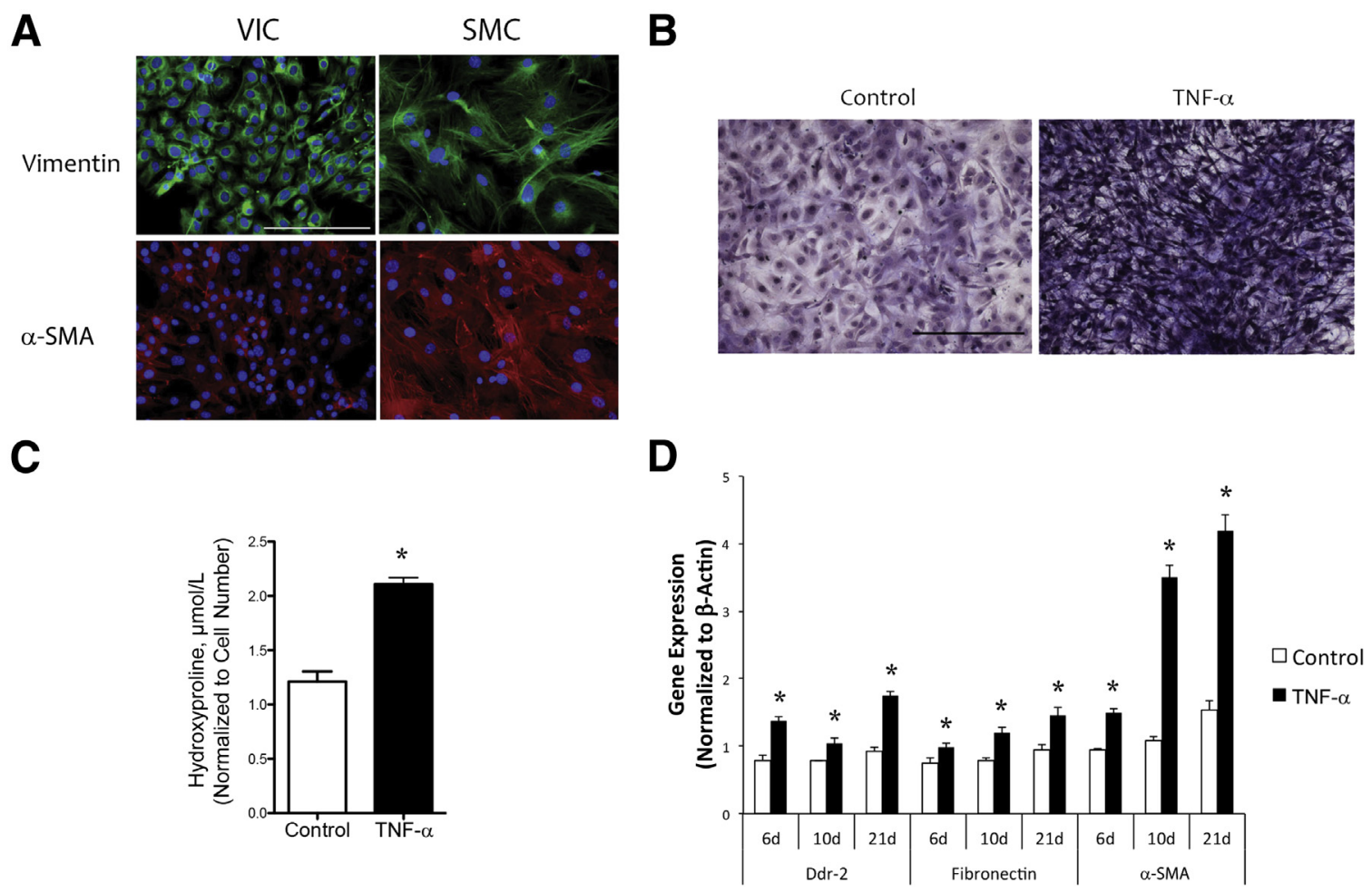

Figure 3 Role of tumor necrosis factor (TNF)- $\alpha$ in production of collagen and expression of cytoskeletal and matrix proteins in primary murine valvular interstitial cells (VICs). A: Myofibroblast markers. VICs and aortic smooth muscle cells (SMCs) were cultured and immunostained with antibodies to vimentin (green) and $\alpha$-smooth muscle actin ( $\alpha$-SMA, red). Nuclei were counterstained with DAPI (blue). B: Collagen deposition. VICs were seeded in $96-$ well plates and treated with control vehicle or $25 \mathrm{ng} / \mathrm{mL}$ of TNF- $\alpha$ for 14 days, and collagen deposition was visualized by Masson's trichrome staining. C: VICs were seeded in 6 well plates and treated with control or $25 \mathrm{ng} / \mathrm{mL}$ of TNF- $\alpha$ for 14 days, and collagen content was quantified by the hydroxyproline assay. D: Gene expression. VICs were seeded in 6 -well plates and treated with control vehicle or $25 \mathrm{ng} / \mathrm{mL}$ of TNF- $\alpha$ for the indicated periods. Total RNA was isolated, and real-time quantitative RT-PCR was performed for the indicated genes. ${ }^{*} P<0.05$ versus control vehicle on the respective day. Scale bar $=100 \mu \mathrm{m}(\mathbf{A}$ and $\mathbf{B})$.

To assess changes in the alignment of collagen fibrils in each layer, second harmonic generation imaging was performed on the calcified versus noncalcified cusps that were immunostained with CellMask Green and DAPI. Compared with the noncalcified tissue, the collagen fibrils in the fibrosa layer of the calcified tissue were more disorganized, with the loss of the regular spacing present in the noncalcified tissue (Figure 2, A and B). In addition, there were clusters of rounded cells near the aortic surface of the fibrosa layer in the calcified tissue, which was not observed in the noncalcified tissue (Figure 2, A and B). Similarly, in the spongiosa layer of the calcified tissue, the collagen fibrils were more densely packed and disorganized compared with the noncalcified tissue (Figure 2, C and D). Interestingly, the collagen fibrils in the ventricularis layer of the calcified tissue contained organized but more densely packed fibrils compared with those in the noncalcified tissue (Figure 2, E and F).

\section{Effects of Inflammation on Cytoskeletal and Extracellular Matrix Proteins}

To test whether inflammation affects collagen production, we performed in vitro cell culture studies using VICs isolated from mouse aortic valve leaflets and cultured via an explant technique. The murine VICs tested positive for myofibroblast markers, vimentin, and a low level of $\alpha$-SMA, but negative for an endothelial marker, von Willebrand factor ${ }^{14}$ (data not shown), consistent with the findings in porcine VICs by the Simmons laboratory (Figure 3A). ${ }^{25,30}$

VICs were treated with an inflammatory cytokine, TNF- $\alpha$, and assays for collagen production and mRNA expression of proteins that interact with collagen were performed. Collagen content was increased in TNF- $\alpha$-treated cells based on Masson's trichrome staining (Figure 3B), similar to the dense collagen production seen in calcified versus noncalcified human aortic valve cusps (Figure 1, E and F). Hydroxyproline assay confirmed that TNF- $\alpha$-treated VICs had significantly greater collagen content than the controls (Figure 3C). TNF- $\alpha$ also up-regulated the mRNA expression of fibronectin, $\alpha$-SMA, and the collagen receptor, discoidin domain tyrosine kinase receptor 2 (Figure 3D). The findings suggest that TNF$\alpha$ induces production of collagen, cytoskeletal actin, and extracellular matrix proteins and proteins that mediate the interaction of the cytoskeleton with extracellular matrix.

\section{Effects of TNF- $\alpha$ on Retraction, Formation of Calcified Nodules, and Stiffness}

To simulate the environment experienced by valve cells in the cusps, which have free edges, we used a 3-D VIC 


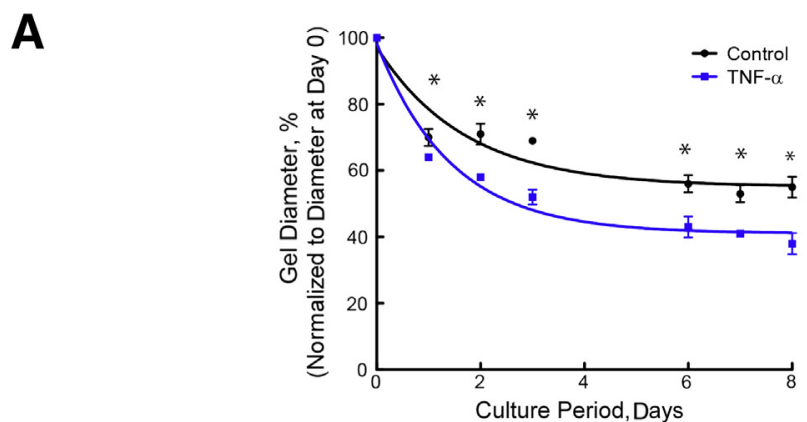

B

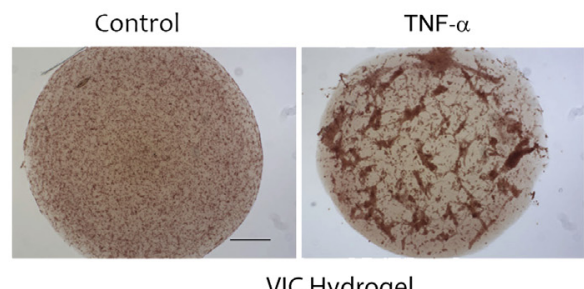

VIC Hydroge

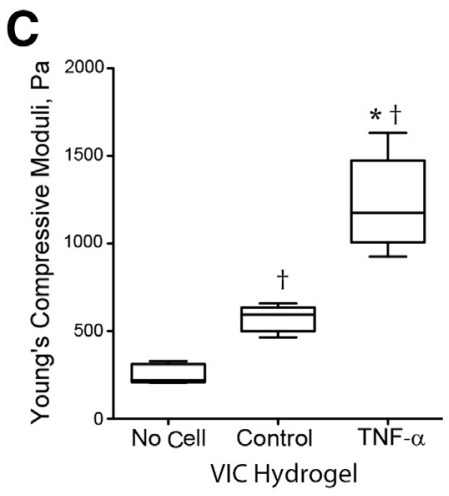

\section{D}

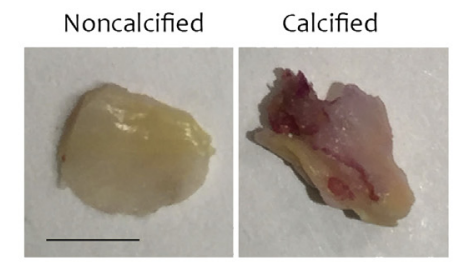

Human Aortic Valve

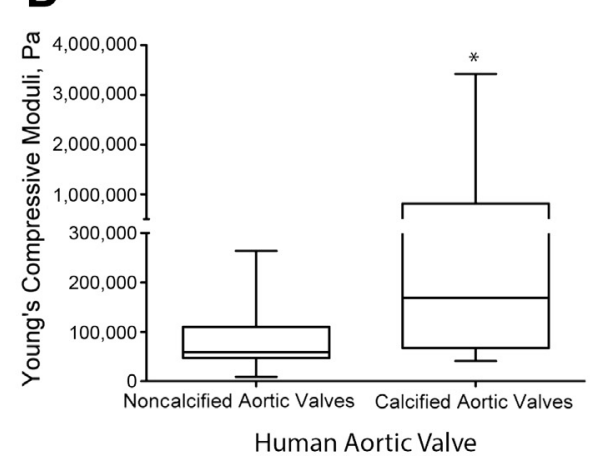

Figure 4 Effects of tumor necrosis factor (TNF) $-\alpha$ on retraction, stiffness, and formation of nodular structures. A: Retraction. Valvular interstitial cells (VICs) were seeded in threedimensional collagen hydrogels (3-D VIC hydrogels) and treated with control vehicle or $25 \mathrm{ng} / \mathrm{mL}$ of TNF- $\alpha$ (for the indicated periods). The diameters of the hydrogels were normalized to the respective diameter at day 0. B: Nodular structures. Left: The 3-D VIC hydrogels were treated with control vehicle or $25 \mathrm{ng} / \mathrm{mL}$ of TNF- $\alpha$ (for 14 days), and the gels were stained with Alizarin Red, mounted on slides, and visualized by light microscopy. Right: The human aortic valve tissues were fixed and stained with Alizarin Red. C: Stiffness of the 3-D VIC hydrogels. Linear compressive testing was performed on hydrogels containing no cells or cells treated with control vehicle or $25 \mathrm{ng} / \mathrm{mL}$ of TNF- $\alpha$ for 8 days, and Young's compressive moduli were determined. D: Stiffness of human aortic valve tissue. The deidentified noncalcified or calcified aortic valve tissues were obtained, and Instron compressive testing was performed. $n=8$ noncalcified, $n=12$ calcified (D). ${ }^{\star} P<0.05$ versus control vehicle on the respective day (A); ${ }^{*} P<0.05$ versus control $(\mathbf{C}) ;{ }^{\dagger} P<0.05$ versus no cell (C); ${ }^{*} P<0.05$ (D). Scale bars: $200 \mu \mathrm{m}$ (B, left) and $3 \mathrm{~mm}$ (B, right). hydrogel model, a free-floating and compliant substrate, modified from that originally developed by Bell and colleagues. ${ }^{29}$ We tested the effects of an inflammatory cytokine, TNF- $\alpha$, on retraction, nodule formation, and stiffening of the 3-D VIC hydrogels. TNF- $\alpha$ significantly promoted retraction of the 3-D VIC hydrogels. There was also spontaneous retraction in untreated VIC-laden hydrogels (Figure 4A) but no retraction in no-cell hydrogels (data not shown). Alizarin Red staining revealed that prolonged treatment of 3-D VIC hydrogels with TNF- $\alpha$ for 14 days induced formation of calcified nodular structures (Figure 4B). The calcium deposition in TNF- $\alpha$-induced nodules, normalized to the total area of the gel, was increased compared with the control group $(21.9 \pm 1.3$ versus $10.5 \pm 1.3, P<0.01)$. Alizarin Red-positive nodules were also observed on the fibrosa surface of the human diseased valve cusp (Figure 4B). To test the stiffness of hydrogels, linear compressive testing was performed. In this test, a probe was advanced normally toward the gel at a constant rate, and the force required to displace the material was measured. Stress-strain curves were generated, and the Young's compressive modulus was derived. The 3-D VIC hydrogels treated with TNF- $\alpha$ for 8 days had significantly greater Young's compressive moduli than control (untreated) or no-cell hydrogels (Figure 4C). Notably, hydrogels that contained untreated VICs had greater compressive moduli than no-cell hydrogels. In specimens of calcified human aortic valve cusps, compressive moduli were also significantly greater than in noncalcified human valves (Figure 4D).

To test whether cytoskeletal contraction contributed to the TNF- $\alpha$-induced retraction and stiffness, the VIC hydrogels were cotreated with the myosin II inhibitor blebbistatin. Results indicated that blebbistatin significantly blocked TNF- $\alpha$-induced retraction and stiffness (Figure 5, A and B), suggesting that the retraction and stiffness are attributable to effects on cytoskeletal contraction. Blebbistatin also inhibited calcific nodular structures induced by TNF- $\alpha$ (Figure 5C). Notably, although the hydrogels in the lower panel are at the same magnification as those in the upper panel, they are larger than the field of view because of inhibition of retraction by blebbistatin.

\section{Effects of the Actin Cytoskeleton on TNF- $\alpha$-Induced Retraction and Stiffness}

Because the actin cytoskeleton contributes to wound contracture, including tissue stiffening through rapid, 

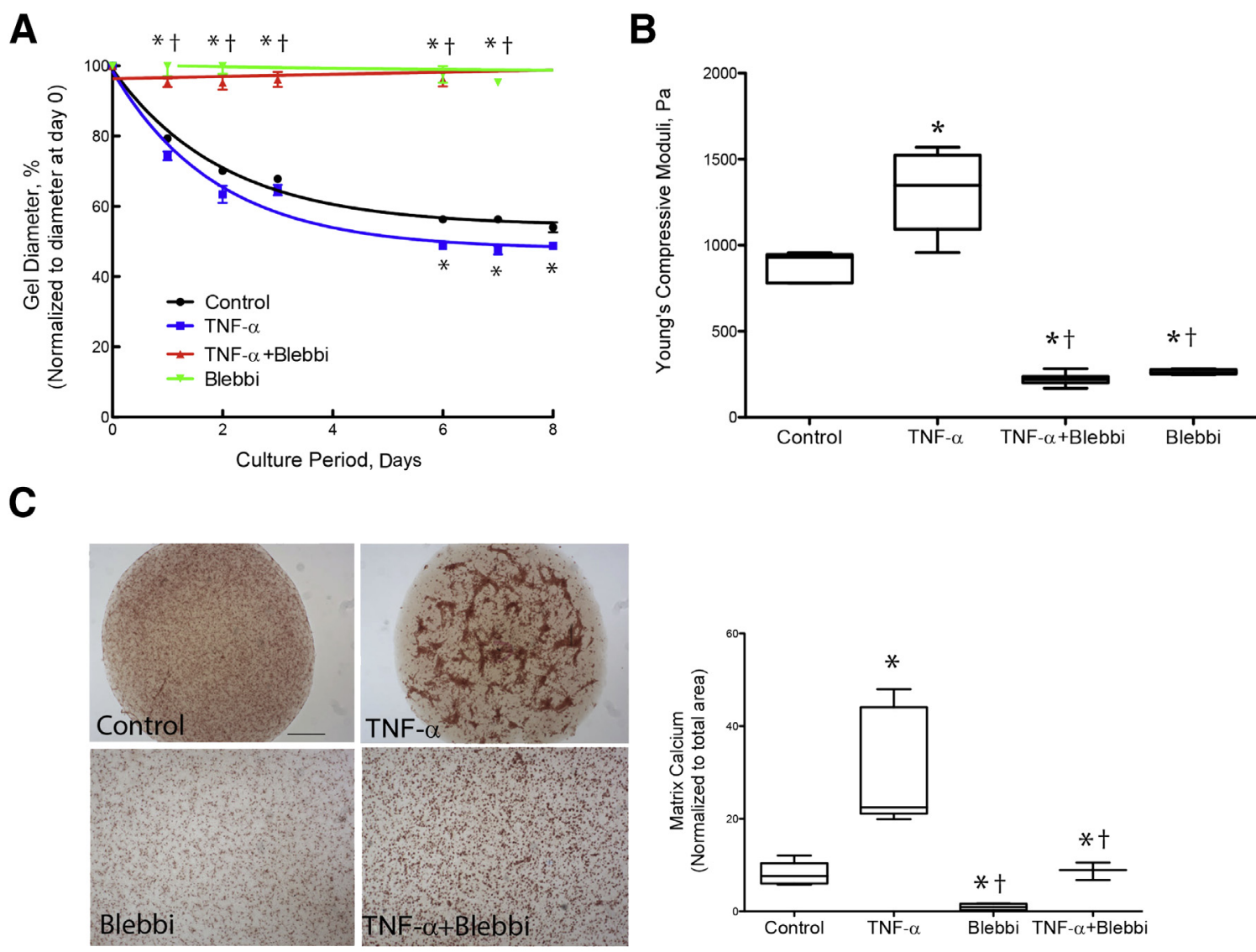

Figure 5 Role of cytoskeletal contraction in tumor necrosis factor (TNF)- $\alpha$-induced retraction and stiffness. A: Retraction. Three-dimensional collagen hydrogels (3-D VIC hydrogels) were treated with control vehicle, $25 \mathrm{ng} / \mathrm{mL}$ of TNF- $\alpha$, and/or $10 \mu \mathrm{mol} / \mathrm{L}$ blebbistatin (Blebbi). The diameters of the hydrogels were normalized to the respective diameters at day 0. B: Stiffness. Linear compressive testing was performed at day 8. C: Nodular structures. After 14 days of treatment, nodule formation was visualized by light microscopy of the hydrogels stained with Alizarin Red. Note that the hydrogels in the lower panel are at the same magnification as those in the upper panel; they are larger than the field of view because of inhibition of retraction by blebbistatin. Matrix calcium deposition in the hydrogels, normalized to total area of the gel, was quantified using ImageJ software version 1.49 . ${ }^{*} P<0.05$ versus control vehicle; ${ }^{\dagger} P<0.05$ versus TNF- $\alpha$ on the respective days. Scale bar $=200 \mu \mathrm{m}$ (C).

dynamic reorganization and contraction, ${ }^{31}$ we next tested the effects of TNF- $\alpha$ on actin filament (F-actin) stress fiber formation. By fluorescent phalloidin staining, TNF- $\alpha$ treatment revealed enhanced accumulation of F-actin bundles (Figure 6A). To inhibit actin polymerization, we treated the hydrogels with cytochalasin D and found significantly less retraction in response to TNF- $\alpha$ (Figure 6B).

Because the Rho signaling pathway is involved in actin stress fiber formation, we used Y27632, a specific inhibitor of Rho-associated protein kinases, to test whether effects of TNF- $\alpha$ depend on actin cytoskeletal assembly and Rhomediated stress fiber formation. Y27632 reduced retraction and stiffness of control and TNF- $\alpha$-treated hydrogels (Figure 6, C and D). Interestingly, it reduced stiffness in control hydrogels to the level of the no-cell hydrogel (Figure 4C), whereas in TNF- $\alpha$-treated hydrogels, Y27632 reduced stiffness only to the level of untreated control hydrogels (Figure 6D). These findings suggest that TNF- $\alpha$ is still capable of inducing stiffening even when Rho kinase is inhibited.

\section{Intracellular Signaling Pathway(s) Mediating TNF- $\alpha$ Effects on Retraction and Stiffness}

To determine the effects of the NF- $\kappa \mathrm{B}$ signaling pathway on TNF- $\alpha$-induced retraction and stiffness of hydrogels, we treated 3-D VIC hydrogels with TNF- $\alpha$. Results revealed activation of NF- $\kappa \mathrm{B}$, as evidenced by increased levels of phospho-IкB immunopositivity (Figure 7A). Western analysis of VICs on two-dimensional cultures confirmed TNF- $\alpha$ activation of NF- $\kappa \mathrm{B}$ by increased phosphorylation of $\mathrm{I} \kappa \mathrm{B}$ and decreased total IKB (Figure 7B). Treatment of the hydrogels with PDTC, an inhibitor of NF- $\kappa \mathrm{B}$ activation, blunted TNF- $\alpha$-induced retraction and stiffness (Figure 7, $\mathrm{C}$ and $\mathrm{D}$ ), suggesting that TNF- $\alpha$ effects were dependent, at least in part, on the NF- $\kappa \mathrm{B}$ signaling pathway. PDTC treatment also inhibited TNF- $\alpha$-induced alkaline phosphatase activity, suggesting that NF- $\kappa \mathrm{B}$ is upstream of osteoblastic differentiation (Figure 7E). Because PDTC not only inhibits NF- $\kappa \mathrm{B}$ but also activates JNK, we further tested the involvement of both signaling pathways using caffeic acid phenethyl ester, which inhibits both NF- $\mathrm{BB}$ and $\mathrm{JNK},{ }^{32}$ or 
A
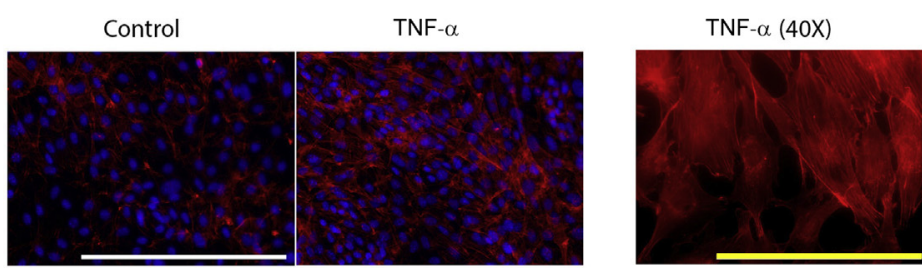

B

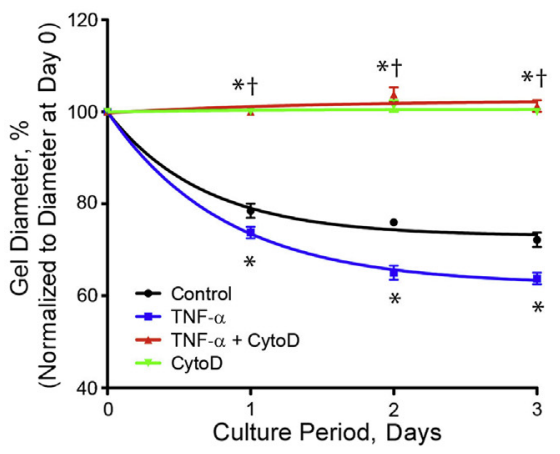

C

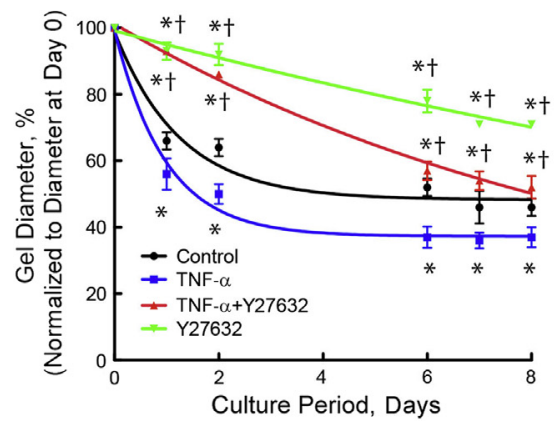

D

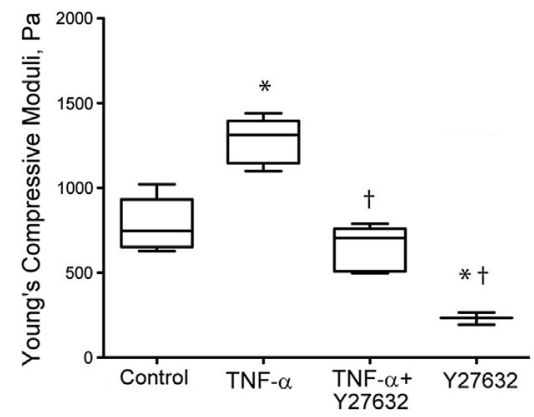

Figure 6 Role of actin cytoskeleton in tumor necrosis factor (TNF)- $\alpha$-induced retraction and stiffness. A: Actin filament stress formation. Valvular interstitial cells (VICs) were cultured on 8-well chamber slides and treated with vehicle control (left) or $25 \mathrm{ng} / \mathrm{mL}$ TNF- $\alpha$ for 7 days, and phalloidin staining (red) was performed. Nuclei were counterstained with DAPI (blue). For the filament structure, a higher magnification of TNF- $\alpha$-treated cells is shown in the right panel. B: Retraction in response to cytochalasin D inhibition of actin filament polymerization. VICs were seeded in three-dimensional hydrogels and treated with control vehicle, $25 \mathrm{ng} / \mathrm{mL}$ of TNF- $\alpha$, and/or $1 \mu \mathrm{mol} / \mathrm{L}$ cytochalasin D (CytoD). The diameters of the hydrogels were normalized to the respective diameters at day 0. C and D: Retraction and stiffness in response to inhibition of Rho kinase. VICs were seeded in three-dimensional hydrogels and treated with control vehicle, $25 \mathrm{ng} / \mathrm{mL} \mathrm{TNF}-\alpha$, and/or $10 \mu \mathrm{mol} / \mathrm{L} \mathrm{Y27632.} \mathrm{The} \mathrm{diameters} \mathrm{of} \mathrm{the}$ hydrogels were normalized to the respective diameters at day 0 . Linear compressive testing was performed at day 8 . ${ }^{*} P<0.05$ versus control vehicle; ${ }^{\dagger} P<0.05$ versus TNF- $\alpha$ on the respective day. White scale bar $=200 \mu \mathrm{m}(\mathbf{A})$. Yellow scale bar $=100 \mu \mathrm{m}(\mathbf{A})$.
SP600125, which inhibits JNK. Both caffeic acid phenethyl ester and SP600125 significantly inhibited TNF- $\alpha$-induced retraction (Figure 8, A and C). Interestingly, both inhibitors failed to attenuate TNF- $\alpha$-induced stiffness (Figure $8, \mathrm{~B}$ and D). These findings suggest that TNF- $\alpha$-induced retraction appears to require activation of the $N F-\kappa B$ signaling pathway, whereas $\mathrm{TNF}-\alpha$-induced stiffening appears to require activation of $\mathrm{NF}-\kappa \mathrm{B}$ with simultaneous inhibition of JNK signaling.

We and others have previously found that TNF- $\alpha$ promotes matrix calcification through induction of bone morphogenetic protein (BMP)-2. ${ }^{14,33,34}$ Therefore, to test whether the BMP-2 signaling pathway is also involved in TNF- $\alpha$-induced retraction and stiffness, we used VICs deficient in one of the pathway's inhibitory molecules: Smad6. In our previous report, we found that Smad6 levels were reduced by $50 \%$ in Smad6 knockdown VICs. ${ }^{14}$ Collagen hydrogels were seeded with lentiviral-transduced VICs (control shRNA or Smad6 shRNA), and retraction and stiffness were assessed. TNF- $\alpha$ increased retraction and stiffness to a similar degree in both control and Smad6 knockdown 3-D VIC hydrogels, suggesting that the TNF- $\alpha$ effects are independent of the BMP-2 signaling pathway (Figure 9, A and B). Interestingly, TNF$\alpha$-induced matrix calcification was augmented in Smad6 knockdown VIC hydrogels compared with those in control hydrogels (Figure 9C), suggesting that BMP-2 signaling is able to induce osteogenic programming independently of the lack of effect on matrix remodeling. Nuclear localization of phospho-Smad1/5/8 was also increased in the hydrogels with TNF- $\alpha$-induced matrix stiffening (Figure 9D), suggesting that TNF- $\alpha$-induced matrix stiffening alters Smad1/5/8 nuclear localization.

\section{Discussion}

Increased accumulation of inflammatory cells and changes in extracellular matrix composition have been reported previously in valve cusps. ${ }^{35}$ In the present study, using histochemistry and laser second harmonic generation, we found that the collagen content is increased in each layer of the human diseased valve cusps and that the alignment of collagen is disorganized, especially in the fibrosa layer of the calcified cusp. Our findings are similar to those of the previous report, ${ }^{36}$ which found, by second harmonic generation imaging, thickened and disordered collagen fibers in the atheroma of swine artery walls compared with the aligned fibers in the normal arteries. 

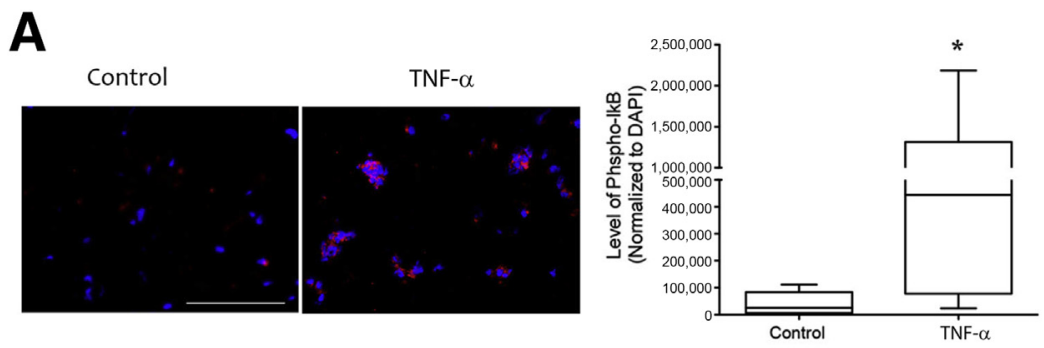

B

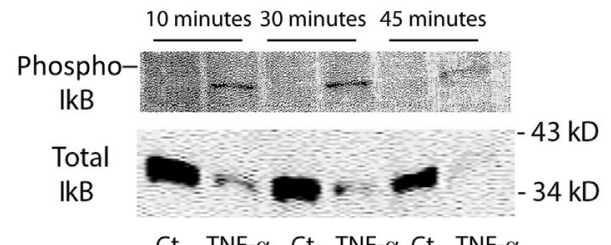

Ct TNF- $\alpha$ Ct TNF- $\alpha$ Ct TNF- $\alpha$

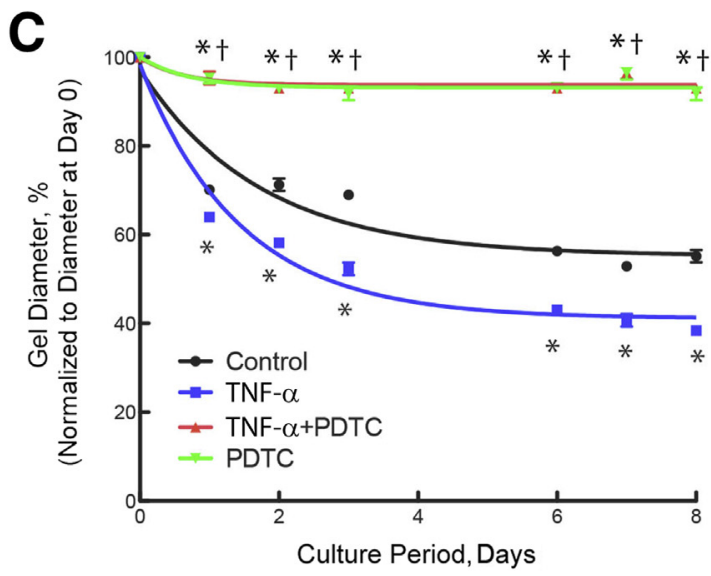

D

E

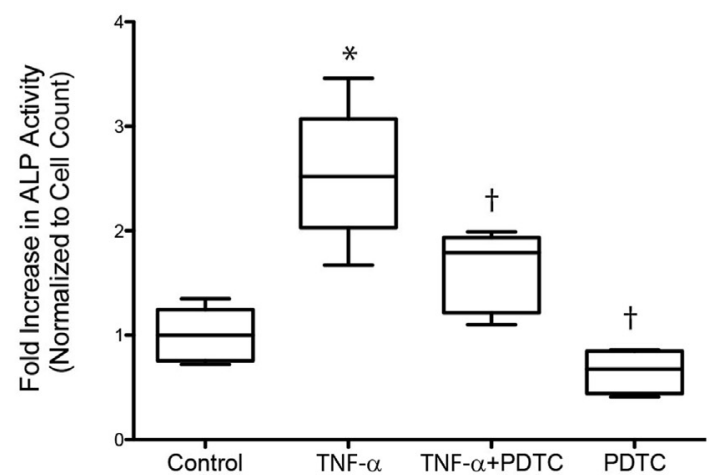

Figure 7 Role of NF- $\kappa$ B in tumor necrosis factor (TNF)- $\alpha$-induced retraction, stiffness, and osteogenic differentiation. A: Immunofluorescence of NF- $\kappa B$ activation. Valvular interstitial cells (VICs) were seeded in three-dimensional hydrogels and treated with control vehicle or $25 \mathrm{ng} / \mathrm{mL}$ of TNF- $\alpha$ for 8 days, embedded in OCT, and cryosectioned. Slides were immunostained with antibody specific to phosphorylated IкB (red), the images were acquired with 0lympus IX71, and the immunofluorescence was quantified using image analysis software (Metamorph Advanced version 7.7). Nuclei were counterstained with DAPI (blue). B: Western analysis of NF- $\mathrm{KB}$ activation. VICs were seeded in 6-well culture dishes, treated with control vehicle or $25 \mathrm{ng} / \mathrm{mL}$ of TNF- $\alpha$ for the indicated

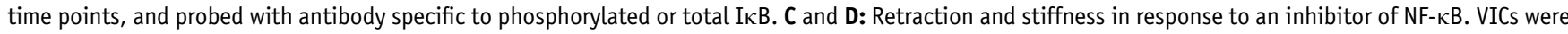
seeded in three-dimensional hydrogels and treated with control vehicle, $25 \mathrm{ng} / \mathrm{mL}$ of TNF- $\alpha$, and/or $10 \mu \mathrm{mol} / \mathrm{L}$ pyrrolidine dithiocarbamate (PDTC). The diameters of the hydrogels were normalized to the respective diameters at day 0 . Instron compressive testing was performed at day 8 . E: VICs were seeded in 96-well plates and treated with control vehicle, $25 \mathrm{ng} / \mathrm{mL}$ of TNF- $\alpha$, and/or $10 \mu \mathrm{mol} / \mathrm{L}$ PDTC. Alkaline phosphatase (ALP) cytochemistry, normalized to cell count, was assessed after 7 days of treatment. ${ }^{\star} P<0.05$ versus control vehicle; ${ }^{\dagger} P<0.05$ versus TNF- $\alpha$. Scale bar $=100 \mu \mathrm{m}(\mathbf{A})$.

We and others have previously reported that the proinflammatory cytokine TNF- $\alpha$ is a potent osteogenic factor in valvular and vascular cells. ${ }^{13,14,34,37-44}$ In this study, we assessed whether TNF- $\alpha$ also contributes to calcific aortic valve stenosis. To model aortic valve cusp tissue, we used mouse valvular cells cultured in free-floating 3-D VIC hydrogels. TNF- $\alpha$ treatment induced retraction of the gels, formation of calcific nodules, and expression of collagen and other matrix and contractile proteins in the valvular cells. Inhibition of NF- $\kappa \mathrm{B}$ activation blocked the effects of TNF- $\alpha$ on these processes. These findings suggest that inflammation contributes to much of the clinicopathologic picture of human aortic valve disease, including calcification, stiffening, and thickening of the valvular cusps. To our knowledge, this is the first study linking inflammation with the clinical features of aortic stenosis: valvular retraction, stiffening, and formation of calcified nodules.

Our experiments using inhibition of cytoskeletal contraction suggest that valve disease, at least initially, involves not 

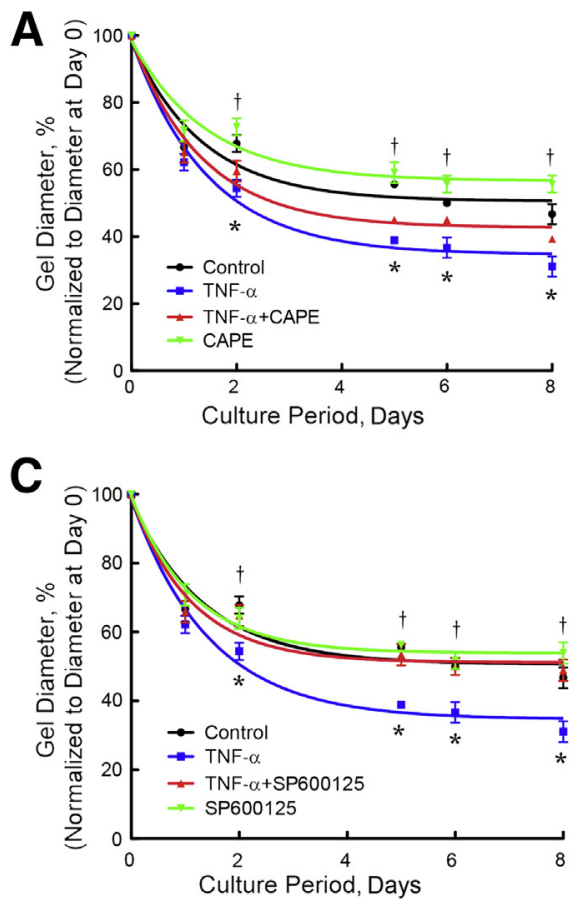
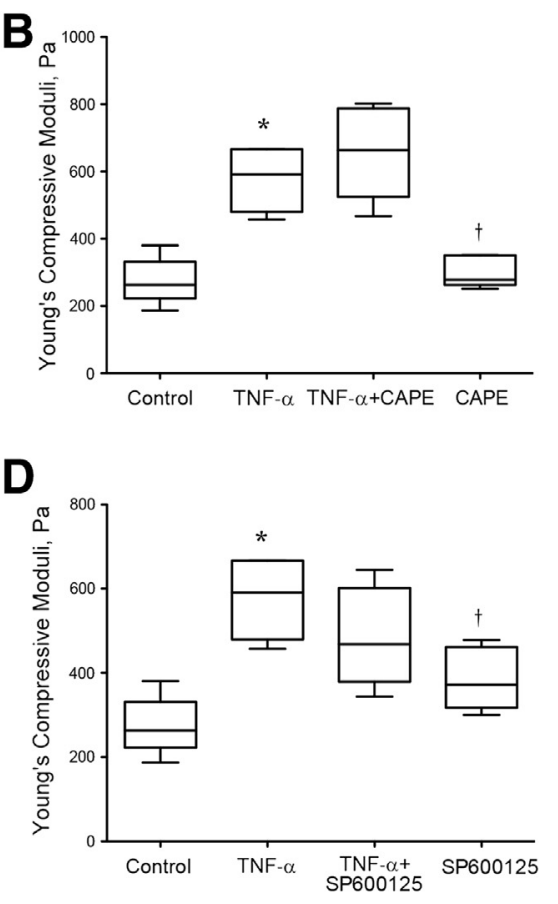

Figure 8 Role of NF- $\kappa$ B and $\mathrm{c}-J u n$ N-terminal kinase in tumor necrosis factor (TNF)- $\alpha$-induced retraction, stiffness, and osteogenic differentiation. $\mathbf{A}$ and $\mathbf{B}$ : Retraction and stiffness in response to caffeic acid phenethyl ester (CAPE). Valvular interstitial cells (VICs) were seeded in threedimensional hydrogels and treated with control vehicle, $25 \mathrm{ng} / \mathrm{mL}$ of TNF- $\alpha$, and/or $5 \mu \mathrm{mol} / \mathrm{L}$ CAPE. The diameters of the hydrogels were normalized to the respective diameters at day 0 . Instron compressive testing was performed at day 8. C and D: Retraction and stiffness in response to SP600125. VICs were seeded in three-dimensional hydrogels and treated with control vehicle, 25 $\mathrm{ng} / \mathrm{mL}$ of TNF- $\alpha$, and/or $10 \mu \mathrm{mol} / \mathrm{L}$ SP600125. The diameters of the hydrogels were normalized to the respective diameters at day 0 . Instron compressive testing was performed at day $8 .{ }^{*} P<0.05$ versus control vehicle; ${ }^{\dagger} P<0.05$ versus TNF- $\alpha$. only deposition of matrix proteins but also active cellular processes, such as cytoskeletal contraction. Interestingly, all three parameters were completely blocked by the inhibitors of actin polymerization and myosin II in both control and TNF- $\alpha$-treated hydrogels. However, inhibition of Rho kinase had more complex results; one explanation may be that inhibition of Rho kinase predominantly affected spontaneous retraction and stiffening. Overall, these findings suggest that cytoskeletal contraction may be integral to stenosis and that TNF- $\alpha$ effects on hydrogel retraction and stiffness are primarily dependent on F-actin assembly and disassembly and actin-myosin interaction. One may even speculate that other forms of stenosis, such as coronary stenosis and urethral stricture, share features of wound contracture.

In previous work, we found that TNF- $\alpha$ up-regulated expression of the potent osteogenic regulator BMP-2 and

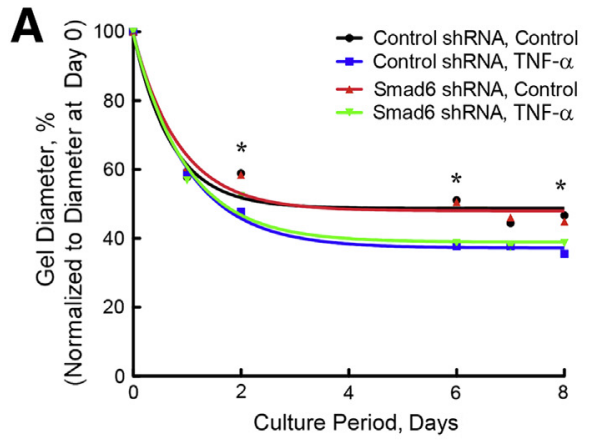

C

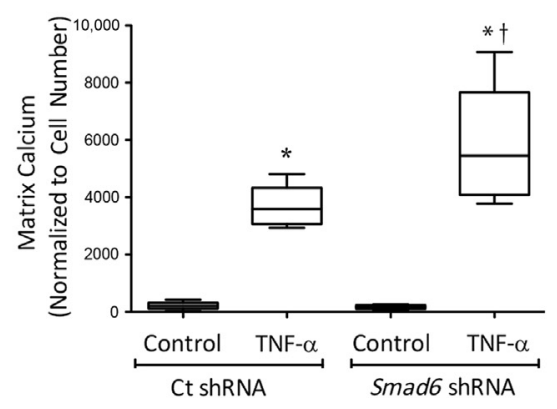

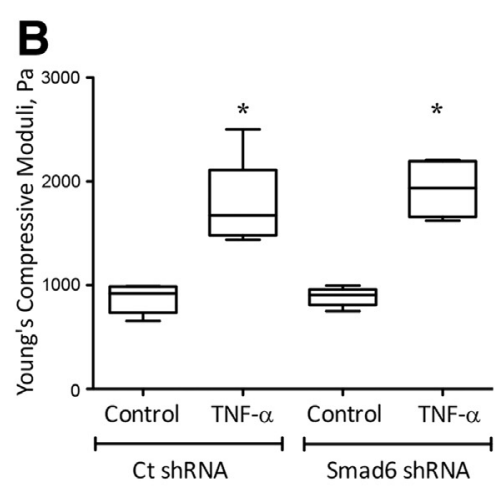

D

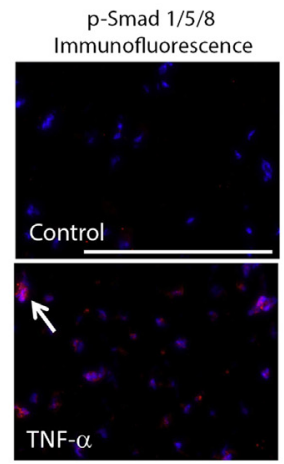

Figure 9 Role of bone morphogenetic protein (BMP)-2 signaling pathway in tumor necrosis factor (TNF)- $\alpha$-induced retraction and stiffness. A and B: Retraction and stiffness. Lentiviraltransduced valvular interstitial cells (VICs) (control shRNA or Smad6 shRNA) were seeded in three-dimensional hydrogels and treated with control vehicle or $25 \mathrm{ng} / \mathrm{mL}$ of TNF- $\alpha$. The diameters of the hydrogels were normalized to the respective diameters at day 0 . Linear compressive testing was performed at day 8. C: Matrix calcification. Lentiviral-transduced VICs (control shRNA or Smad6 shRNA) were seeded in three-dimensional hydrogels and treated with control vehicle or 25 $\mathrm{ng} / \mathrm{mL}$ of TNF- $\alpha$ for 14 days, and matrix calcium was visualized by Alizarin Red staining and quantified using imaging analysis software (Metamorph Advanced version 7.7). D: Phosphorylated Smad1/ $5 / 8$ immunofluorescence. VICs were seeded in three-dimensional hydrogels and treated with control vehicle or $25 \mathrm{ng} / \mathrm{mL}$ of TNF- $\alpha$ for 8 days, embedded in OCT, and cryosectioned. Slides were immunostained with antibody specific to phosphoSmad 1/5/8 (p-Smad 1/5/8) (red, arrow). Nuclei were counterstained with DAPI (blue). ${ }^{*} P<0.05$ versus control vehicle; ${ }^{\dagger} P<0.05$ versus $C$ t shRNA TNF- $\alpha$. Scale bar $=100 \mu \mathrm{m}$ (D). 
increased matrix calcification of VICs. ${ }^{14} \mathrm{We}$ also found that enhancing BMP-2 signaling by knocking down its inhibitor Smad6 further enhanced TNF- $\alpha$-induced matrix calcification. ${ }^{14}$ The present results, contrary to our expectations, indicate that the effects of TNF- $\alpha$ on retraction and stiffness were not altered in Smad6 knockdown VICs, suggesting that the TNF- $\alpha$ effects on retraction and nodule formation appear to be independent of BMP-2 signaling. Nonetheless, the osteogenic programming enabled by TNF- $\alpha$-induced matrix stiffening was accentuated by Smad6 deficiency, suggesting that pro-osteogenic BMP-2 signaling functions downstream of the permissive mechanical environment enabled by TNF- $\alpha$. Moreover, this stiffening resulted in increased BMP-2 signaling, as evidenced by Smad1/5/8 nuclear localization. This finding may be explained by the tensegrity model, inspired by Buckminster Fuller and applied to cellular functions by Ingber. ${ }^{45}$ This model predicts that nuclear function is altered by cell shape, which is, in turn, altered by matrix stiffness. This phenomenon affects nuclear transport. ${ }^{46}$ The broader effect of matrix stiffness was demonstrated famously by Engler et al, ${ }^{47}$ who found that sequential increases in substrate stiffness generated a spectrum of mesenchymal lineage differentiation by multipotent human mesenchymal cells, which was confirmed specifically for osteogenic differentiation of valvular cells. ${ }^{25}$ Thus, inflammatory cytokines, such as TNF- $\alpha$, may ultimately promote osteogenesis at least partly through a tensegrity mechanism attributable to substrate stiffening.

Our working model links inflammation to CAVD through a control circuit as follows: inflammation promotes both passive stiffening, through increased deposition of extracellular matrix proteins (eg, collagen), and active stiffening, through cytoskeletal contraction (eg, myosin II, F-actin assembly). Active and passive stiffening act synergistically through tensegrity and a mechanism proposed by Hinz,${ }^{48}$ in which cell retraction against a stiff matrix transmits forces to the molecular links that connect actin to collagen binding proteins (eg, fibronectin and discoidin domain tyrosine kinase receptor 2), which opens latency-associated peptides to release matrix-bound transforming growth factor- $\beta$, and possibly its family members such as BMP-2, altering differentiation through receptor-activated signaling. Because osteochondrogenic differentiation and calcification would further increase matrix stiffness, a positive feedback loop ensues. Moreover, matrix stiffness is also known to increase responsiveness to TNF- $\alpha,{ }^{7}$ thus leading to a second positive feedback loop. One or more of these processes may be ideal targets for developing treatment of calcific valvulopathy.

\section{Acknowledgments}

We thank Dr. Benjamin Wu for the use of the Bioengineering instrumentation and Chase Linsley for technical assistance. Second harmonic generation microscopy was performed at the California NanoSystems Institute
Advanced Light Microscopy/Spectroscopy Shared Resource Facility at UCLA.

\section{References}

1. Cowell SJ, Newby DE, Boon NA, Elder AT: Calcific aortic stenosis: same old story? Age Ageing 2004, 33:538-544

2. Vahanian A, Alfieri O, Andreotti F, Antunes MJ, Baron-Esquivias G Baumgartner H, Borger MA, Carrel TP, De Bonis M, Evangelista A, Falk V, Lung B, Lancellotti P, Pierard L, Price S, Schafers HJ, Schuler G, Stepinska J, Swedberg K, Takkenberg J, Von Oppell UO, Windecker S, Zamorano JL, Zembala M; Joint Task Force on the Management of Valvular Heart Disease of the European Society of Cardiology (ESC); European Association for Cardio-Thoracic Surgery (EACTS): Guidelines on the management of valvular heart disease (version 2012): the Joint Task Force on the Management of Valvular Heart Disease of the European Society of Cardiology (ESC) and the European Association for Cardio-Thoracic Surgery (EACTS). Eur J Cardiothorac Surg 2012, 42:S1-S44

3. Lindroos M, Kupari M, Heikkila J, Tilvis R: Prevalence of aortic valve abnormalities in the elderly: an echocardiographic study of a random population sample. J Am Coll Cardiol 1993, 21:1220-1225

4. Otto CM, Lind BK, Kitzman DW, Gersh BJ, Siscovick DS: Association of aortic-valve sclerosis with cardiovascular mortality and morbidity in the elderly. N Engl J Med 1999, 341:142-147

5. Stewart BF, Siscovick D, Lind BK, Gardin JM, Gottdiener JS, Smith VE, Kitzman DW, Otto CM: Clinical factors associated with calcific aortic valve disease: Cardiovascular Health Study. J Am Coll Cardiol 1997, 29:630-634

6. Chen JH, Simmons CA: Cell-matrix interactions in the pathobiology of calcific aortic valve disease: critical roles for matricellular, matricrine, and matrix mechanics cues. Circ Res 2011, 108:1510-1524

7. Nakasaki M, Hwang Y, Xie Y, Kataria S, Gund R, Hajam EY, Samuel R, George R, Danda D, MJ P, Nakamura T, Shen Z, Briggs S, Varghese S, Jamora C: The matrix protein Fibulin-5 is at the interface of tissue stiffness and inflammation in fibrosis. Nat Commun 2015, 6:8574

8. Gondrie MJ, van der Graaf Y, Jacobs PC, Oen AL, Mali WP: The association of incidentally detected heart valve calcification with future cardiovascular events. Eur Radiol 2011, 21:963-973

9. O'Rourke RA, Brundage BH, Froelicher VF, Greenland P, Grundy SM, Hachamovitch R, Pohost GM, Shaw LJ, Weintraub WS, Winters WL Jr, Forrester JS, Douglas PS, Faxon DP, Fisher JD, Gregoratos G, Hochman JS, Hutter AM Jr, Kaul S, Wolk MJ: American College of Cardiology/American Heart Association Expert Consensus document on electron-beam computed tomography for the diagnosis and prognosis of coronary artery disease. Circulation 2000, 102:126-140

10. Rennenberg RJ, Kessels AG, Schurgers LJ, van Engelshoven JM, de Leeuw PW, Kroon AA: Vascular calcifications as a marker of increased cardiovascular risk: a meta-analysis. Vasc Health Risk Manag 2009, 5:185-197

11. Bruunsgaard H, Skinhoj P, Pedersen AN, Schroll M, Pedersen BK: Ageing, tumour necrosis factor-alpha (TNF-alpha) and atherosclerosis. Clin Exp Immunol 2000, 121:255-260

12. Swierszcz J, Dubiel JS, Krzysiek J, Sztefko K: One-year observation of inflammatory markers in patients with aortic valve stenosis. J Heart Valve Dis 2011, 20:639-649

13. Al-Aly Z, Shao JS, Lai CF, Huang E, Cai J, Behrmann A, Cheng SL, Towler DA: Aortic Msx2-Wnt calcification cascade is regulated by TNF-alpha-dependent signals in diabetic Ldlr-/- mice. Arterioscler Thromb Vasc Biol 2007, 27:2589-2596

14. Li X, Lim J, Lu J, Pedego TM, Demer L, Tintut Y: Protective role of Smad6 in inflammation-induced valvular cell calcification. J Cell Biochem 2015, 116:2354-2364

15. Hanna AN, Berthiaume LG, Kikuchi Y, Begg D, Bourgoin S, Brindley DN: Tumor necrosis factor- $\alpha$ induces stress fiber formation 
through ceramide production: role of sphingosine kinase. Mol Biol Cell 2001, 12:3618-3630

16. Taylor PM, Batten P, Brand NJ, Thomas PS, Yacoub MH: The cardiac valve interstitial cell. Int J Biochem Cell Biol 2003, 35:113-118

17. Desmouliere A, Geinoz A, Gabbiani F, Gabbiani G: Transforming growth factor- $\beta 1$ induces alpha-smooth muscle actin expression in granulation tissue myofibroblasts and in quiescent and growing cultured fibroblasts. J Cell Biol 1993, 122:103-111

18. Ostlund RE, Pastan I, Adelstein RS: Myosin in cultured fibroblasts. J Biol Chem 1974, 249:3903-3907

19. Rabkin-Aikawa E, Farber M, Aikawa M, Schoen FJ: Dynamic and reversible changes of interstitial cell phenotype during remodeling of cardiac valves. J Heart Valve Dis 2004, 13:841-847

20. Li C, Gotlieb AI: Transforming growth factor- $\beta$ regulates the growth of valve interstitial cells in vitro. Am J Pathol 2011, 179:1746-1755

21. Xu S, Gotlieb AI: Wnt3a/ $\beta$-catenin increases proliferation in heart valve interstitial cells. Cardiovasc Pathol 2013, 22:156-166

22. Mohler ER 3rd, Chawla MK, Chang AW, Vyavahare N, Levy RJ, Graham L, Gannon FH: Identification and characterization of calcifying valve cells from human and canine aortic valves. J Heart Valve Dis 1999, 8:254-260

23. Mohler ER 3rd, Gannon F, Reynolds C, Zimmerman R, Keane MG, Kaplan FS: Bone formation and inflammation in cardiac valves. Circulation 2001, 103:1522-1528

24. Pho M, Lee W, Watt DR, Laschinger C, Simmons CA, McCulloch CA: Cofilin is a marker of myofibroblast differentiation in cells from porcine aortic cardiac valves. Am J Physiol Heart Circ Physiol 2008, 294:H1767-H1778

25. Yip CY, Chen JH, Zhao R, Simmons CA: Calcification by valve interstitial cells is regulated by the stiffness of the extracellular matrix. Arterioscler Thromb Vasc Biol 2009, 29:936-942

26. Hjortnaes J, Camci-Unal G, Hutcheson JD, Jung SM, Schoen FJ, Kluin J, Aikawa E, Khademhosseini A: Directing valvular interstitial cell myofibroblast-like differentiation in a hybrid hydrogel platform. Adv Healthc Mater 2015, 4:121-130

27. Theodossiou TA, Thrasivoulou C, Ekwobi C, Becker DL: Second harmonic generation confocal microscopy of collagen type I from rat tendon cryosections. Biophys J 2006, 91:4665-4677

28. Neu TR, Kuhlicke U, Lawrence JR: Assessment of fluorochromes for two-photon laser scanning microscopy of biofilms. Appl Environ Microbiol 2002, 68:901-909

29. Bell E, Ivarsson B, Merrill C: Production of a tissue-like structure by contraction of collagen lattices by human fibroblasts of different proliferative potential in vitro. Proc Natl Acad Sci U S A 1979, 76:1274-1278

30. Chen JH, Yip CY, Sone ED, Simmons CA: Identification and characterization of aortic valve mesenchymal progenitor cells with robust osteogenic calcification potential. Am J Pathol 2009, 174:1109-1119

31. dos Remedios CG, Chhabra D, Kekic M, Dedova IV, Tsubakihara M, Berry DA, Nosworthy NJ: Actin binding proteins: regulation of cytoskeletal microfilaments. Physiol Rev 2003, 83:433-473

32. Natarajan K, Singh S, Burke TR Jr, Grunberger D, Aggarwal BB: Caffeic acid phenethyl ester is a potent and specific inhibitor of activation of nuclear transcription factor NF-kappa B. Proc Natl Acad Sci U S A 1996, 93:9090-9095

33. Fukui N, Ikeda Y, Ohnuki T, Hikita A, Tanaka S, Yamane S, Suzuki R, Sandell LJ, Ochi T: Pro-inflammatory cytokine tumor necrosis factor-alpha induces bone morphogenetic protein-2 in chondrocytes via mRNA stabilization and transcriptional up-regulation. J Biol Chem 2006, 281:27229-27241

34. Yu Z, Seya K, Daitoku K, Motomura S, Fukuda I, Furukawa K: Tumor necrosis factor-alpha accelerates the calcification of human aortic valve interstitial cells obtained from patients with calcific aortic valve stenosis via the BMP2-D1x5 pathway. J Pharmacol Exp Ther 2011, 337:16-23

35. Freeman RV, Otto CM: Spectrum of calcific aortic valve disease: pathogenesis, disease progression, and treatment strategies. Circulation 2005, 111:3316-3326

36. Le TT, Langohr IM, Locker MJ, Sturek M, Cheng JX: Label-free molecular imaging of atherosclerotic lesions using multimodal nonlinear optical microscopy. J Biomed Opt 2007, 12:054007

37. Buendia P, Montes de Oca A, Madueno JA, Merino A, MartinMalo A, Aljama P, Ramirez R, Rodriguez M, Carracedo J: Endothelial microparticles mediate inflammation-induced vascular calcification. FASEB J 2015, 29:173-181

38. Cheng SL, Shao JS, Halstead LR, Distelhorst K, Sierra O, Towler DA: Activation of vascular smooth muscle parathyroid hormone receptor inhibits Wnt/beta-catenin signaling and aortic fibrosis in diabetic arteriosclerosis. Circ Res 2010, 107:271-282

39. Cola C, Almeida M, Li D, Romeo F, Mehta JL: Regulatory role of endothelium in the expression of genes affecting arterial calcification. Biochem Biophys Res Commun 2004, 320:424-427

40. Ikeda K, Souma Y, Akakabe Y, Kitamura Y, Matsuo K, Shimoda Y, Ueyama T, Matoba S, Yamada H, Okigaki M, Matsubara H: Macrophages play a unique role in the plaque calcification by enhancing the osteogenic signals exerted by vascular smooth muscle cells. Biochem Biophys Res Commun 2012, 425:39-44

41. Kaden JJ, Kilic R, Sarikoc A, Hagl S, Lang S, Hoffmann U, Brueckmann M, Borggrefe M: Tumor necrosis factor $\alpha$ promotes an osteoblast-like phenotype in human aortic valve myofibroblasts: a potential regulatory mechanism of valvular calcification. Int J Mol Med 2005, 16:869-872

42. Lai CF, Shao JS, Behrmann A, Krchma K, Cheng SL, Towler DA: TNFR1-activated reactive oxidative species signals up-regulate osteogenic Msx2 programs in aortic myofibroblasts. Endocrinology 2012, 153:3897-3910

43. Tintut Y, Patel J, Parhami F, Demer LL: Tumor necrosis factor- $\alpha$ promotes in vitro calcification of vascular cells via the cAMP pathway. Circulation 2000, 102:2636-2642

44. Zhao G, Xu MJ, Zhao MM, Dai XY, Kong W, Wilson GM, Guan Y, Wang CY, Wang X: Activation of nuclear factor- $\kappa \mathrm{B}$ accelerates vascular calcification by inhibiting ankylosis protein homolog expression. Kidney Int 2012, 82:34-44

45. Wang N, Butler JP, Ingber DE: Mechanotransduction across the cell surface and through the cytoskeleton. Science 1993, 260: $1124-1127$

46. Jiang LW, Schindler M: Nuclear transport in $3 \mathrm{~T} 3$ fibroblasts: effects of growth factors, transformation, and cell shape. J Cell Biol 1988, 106: 13-19

47. Engler AJ, Sen S, Sweeney HL, Discher DE: Matrix elasticity directs stem cell lineage specification. Cell 2006, 126:677-689

48. Hinz B: It has to be the alphav: myofibroblast integrins activate latent TGF- $\beta 1$. Nat Med 2013, 19:1567-1568 